\title{
Prevalence of Canine Heartworm Disease in Stray Dogs of Grenada, West Indies
}

\author{
Melissa C. Brown, Alfred Chikweto, Keshaw P. Tiwari, Claude DeAllie, \\ Muhammad Iqbal Bhaiyat, Ravindra N. Sharma*
}

Department of Pathobiology, School of Veterinary Medicine, St. George's University, Grenada, West Indies Email: Melissacelestebrown.mcb@gmail.com, achikweto@sgu.edu, ktiwari@sgu.edu, cdeallie@sgu.edu, mibhaiyat@sgu.edu, ‘rsharma@sgu.edu

How to cite this paper: Brown, M.C., Chikweto, A., Tiwari, K.P., DeAllie, C., Bhaiyat, M.I. and Sharma, R.N. (2017) Prevalence of Canine Heartworm Disease in Stray Dogs of Grenada, West Indies. Open Journal of Veterinary Medicine, 7, 168-174.

https://doi.org/10.4236/ojvm.2017.711018

Received: October 19, 2017

Accepted: November 26, 2017

Published: November 29, 2017

Copyright ( 92017 by authors and Scientific Research Publishing Inc. This work is licensed under the Creative Commons Attribution International License (CC BY 4.0).

http://creativecommons.org/licenses/by/4.0/

\begin{abstract}
Dirofilariasis (heartworm disease) has been reported in Grenadian dogs. The aim of this cross-sectional study was to determine the prevalence of Dirofilaria immitis in stray dogs $(\mathrm{n}=523)$ from the six Parishes of Grenada. Necropsy records were reviewed; information on the distribution and lesions of Dirofilaria immitis was recorded. A total of 144 from 523 dogs (27.5\%; 95\% CI: $23.9 \%$ to $31.5 \%$ ) were positive for Dirofilaria immitis on necropsy. This study shows that heartworm disease is prevalent in stray dogs in all the Parishes of mainland Grenada. This is a progressive, life-threatening disease and thus, there is a need to screen and prevent it within the stray dog population of Grenada.
\end{abstract}

\section{Keywords}

Dirofilaria immitis, Prevalence, Stray Dogs, Necropsy, Grenada

\section{Introduction}

Canine heartworm disease is a mosquito vector-borne disease caused by the filarial nematode, Dirofilaria immitis [1]. The parasite (Dirofilaria immitis) is transmitted by various mosquitoes belonging to the genera Culex, Aedes, Anopheles, Ochlerotatus, and Mansonia [2] [3]. Adult female D. immitis lays microfilariae, which are taken up by suitable mosquito vectors and subsequently develop to the infective 3 rd larval stage. Transmission takes place when a potential vector bites dogs or other hosts during a subsequent blood meal. It takes about 6 - 7 months to become an adult stage. Pathophysiological response to heartworm infection is mainly due to the presence of adult worm in heart and lungs. The main clinical symptoms in dirofilariasis include persistent cough, difficult 
breathing, and poor exercise tolerance followed by ascites, anorexia, and weight loss. The disease is more prevalent in warm tropical and subtropical regions of the world where the conditions are favorable for mosquitoes to thrive. [2] [4].

The impact of $D$. immitis infections on companion animal health and veterinary practice in endemic areas cannot be overemphasized [5]. In endemic areas, where prophylaxis is irregular, the prevalence of $D$. immitis infection can be as high as $20 \%$ [5]. The necessary conditions for the transmission of heartworm disease are encountered all year-round, and can be augmented by human and animal migration, as well as, by possible climate change [6]. All these factors are also observed in Grenada; humans and their dogs travel constantly for various purposes such as, education or vacation.

Dirofilaria immitis originated in Asia, had a long history in countries bordering the Mediterranean, and was brought to the Americas via dogs by the early explorers and immigrants [7]. Canine heartworm disease has been known to exist in the Americas for more than 150 years (1847), and the first South American report was published approximately 30 years later (1875), followed by Japan in 1880, and almost 90 years later in Iran [8] [9] [10]. Limited literature is available on the prevalence of $D$. immitis infection in the Caribbean and South America [8] [11]. The following are prevalence levels of D. immitis in dogs in the Caribbean region: Turks and Caicos island (58\% in stray dogs and $8 \%$ in owned dogs) [12]; Puerto Rico (20\%) [11]; Curacao (11\%) [11]; Grand Bahamas (53\%) [11]. In Grenada, Chikweto et al. [13] found $15.4 \%$ prevalence of $D$. immitis in owned dogs. Therefore, the objective of this study was to compare the prevalence of $D$. immitis in stray dogs with previous report in owned dogs in Grenada.

\section{Materials and Methods}

\subsection{Country of Research}

Grenada is a Caribbean island between the Caribbean Sea and Atlantic Ocean, north of Trinidad and Tobago. It is located at $12^{\circ}$ north of the equator and approximately 200 miles north of Trinidad and Tobago. Grenada is a tri-island state comprised of Grenada, Carriacou and Petite Martinique. Grenada is the largest of the three islands and is divided into 6 parishes namely St. George, St. John, St. Mark, St. Patrick, St. Andrew, and St. David. St. George's University is located at the southernmost tip of the island in the second largest parish, St. George. The Grenadian climate is tropical and wet, tempered by northeast trade winds. The wet season runs from June through November and rainfall is less pronounced from December through May. Similarly, the highest humidities (80\%) are recorded during the rainy months, and values from $68 \%$ to $78 \%$ are registered during the drier period. Temperatures averaging $29^{\circ} \mathrm{C}$ are constant throughout the year. Diurnal ranges within a 24 -hour period are between $26^{\circ} \mathrm{C}$ and $32^{\circ} \mathrm{C}$ during the day and between $19^{\circ} \mathrm{C}$ and $24^{\circ} \mathrm{C}$ at night. The temperature and humidity provide suitable conditions for development of the mosquito as well as for the larvae (L1-L3) of D. immitis in the vectors [1]. The presence of 
these climatic conditions in Grenada and the importance of stray dogs as reserve host of the infection in its transmission to other animals, and even humans, necessitated this study.

\subsection{Collection of Samples}

This work was facilitated by collaboration in a program with the Veterinary and Livestock Division of the Ministry of Agriculture, Lands, Forestry \& Fisheries in conjunction with the Ministry of Health and Social Security. In this stray dog control program, stray dogs were impounded, euthanized and submitted for necropsy to the Pathology Laboratory of the School of Veterinary Medicine at St. George's University. A total of 523 stray dogs from the six different parishes of Grenada were trapped in five years, between 2008 and 2013. At the time of necropsy, observation was made on the physical condition of the carcass. A distinction of sex and a rough estimation of the age of the dogs (puppy, juvenile and adult) was also made. A complete necropsy was performed on each dog with special attention given to the heart and the lungs. Necropsy was under taken within 24 - 48 hours following euthanasia. Dogs with thread like worms, D. immitis, in heart and or lungs were recorded as positive. However, nematodes were not counted, but a semi-quantitative classification (mild, moderate and severe) was done. The degree of infection was subjectively divided into mild (1 - 10 nematodes), moderate (10 - 20 nematodes) and severe ( $>20$ nematodes) in the heart and pulmonary vasculature. A few worms taken from heart/lungs were examined under a light microscope for identification. These worms were identified following the description of $D$. immitis by Bowman [12].

\subsection{Statistical Analysis of Data}

Confidence interval for prevalence and comparison of prevalence values between stray and owned dogs were calculated using a graphpad statistical software (http://www.graphpad.com/quickcalcs/). Briefly, the number of heartworm positive stray dogs was divided by the total number of stray dogs in order to obtain a proportion of positive dogs. The proportion was used to calculate the confidence interval at $95 \%$ level of confidence. Four by four contingency tables were created and subsequently used for calculation of p-value.

\subsection{Ethical Statement}

The Ministry of health routinely euthanizes stray dogs in order to control the population of these dogs. Approval to euthanize the stray dogs was obtained from the Government of Grenada. On our part, it was not necessary to obtain approval from the Institution of animal care and use Committee University (IACUC) at St. George's since the animals submitted to us were not alive.

\section{Limitations of This Study}

The present study was based on stray dogs that were euthanized by the Ministry 
of health and submitted to the necropsy facility at St. George's University. The Ministry of health routinely controls stray dogs by euthanizing them. Since the sampling method was not random in nature, it could result in a biased estimate of prevalence. However, this deficiency was compensated for by a large sample size of 523 stray dogs. Since the dogs were euthanized by separate persons, it was not possible to observe clinical signs of heartworm disease in the stray dogs. Finally, since the dogs were stray, it was not possible to get the exact age.

\section{Results}

Out of the 523 dogs ( 280 females and 243 males) that were necropsied, 144 (72 females and 72 males) were positive for $D$. immitis, in the heart and/or lungs (Figure 1), with an overall prevalence of $27.5 \%$ (95\% CI: $23.9 \%$ to $31.5 \%$ ). Examination of worms under light microscope was consistent with the morphology of $D$. immitis. The total number of dogs necropsied with the corresponding number of dogs infected with $D$. immitis, according to Parish, are shown in Table 1. The number of dogs infected with $D$. immitis according to Parish in descending order was as follows: St. Andrew (58\%); St. David (51\%); St. Patrick (36\%); St. John (32\%); St. George (24\%); St. Mark (9\%).

All the stray dogs were of a mixed local breed, also referred to as Grenadian pothound. Pothounds are the most common type of dog in Grenada. Table 2 shows categories of dogs thus: puppy; juvenile and adult. Severity of heartworm infection according to age group is also depicted in the same table. All the worms examined were adults, they ranged from 3.2 to $11 \mathrm{~cm}$ in length. The worms were not counted and not grouped into males and females.

In the stray dogs with moderate and severe worm burdens, the right ventricle was often dilated and there was subsequent chronic passive congestion in the liver.

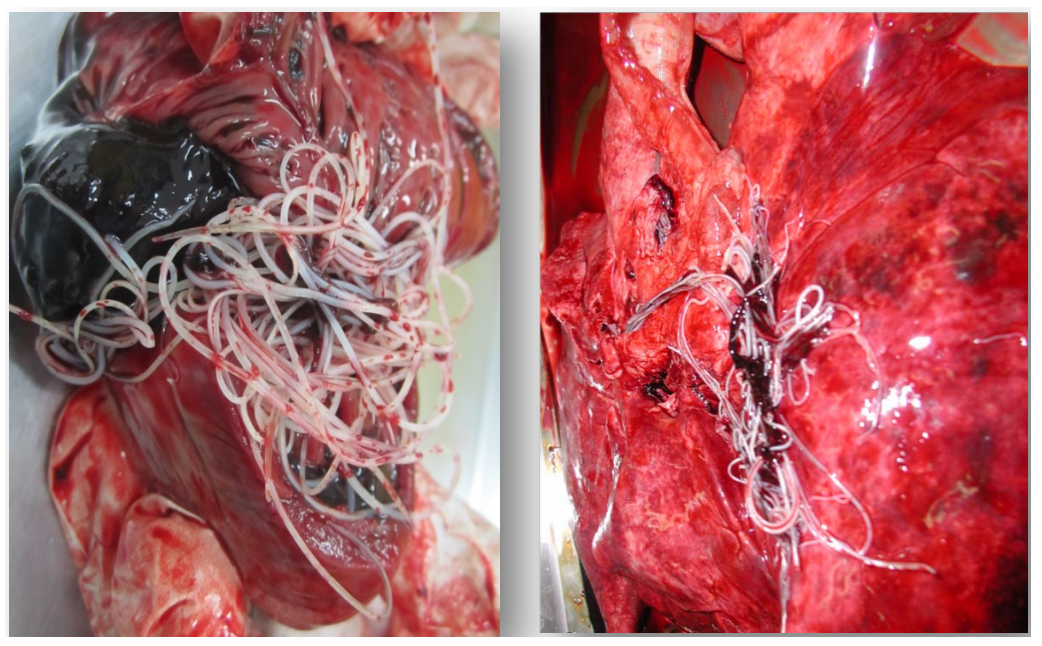

Figure 1. Heartworm infection in a dog. Numerous adult Dirofilaria immitis are present in the right atrium and ventricle (left) and in branches of the pulmonary artery of the lung (right). 
Table 1. Prevalence of $D$. immitis in stray dogs in the different Parishes of Grenada.

\begin{tabular}{cccc}
\hline Parish & Number of dogs necropsied & Number infected & Percent (\%) infected \\
\hline St. Andrew & 50 & 29 & 58 \\
St. David & 45 & 23 & 51 \\
St. Patrick & 14 & 5 & 36 \\
St. John & 34 & 11 & 32 \\
St. George & 272 & 66 & 24 \\
St. Mark & 108 & 10 & 9 \\
Totals & 523 & 144 & 27.5 \\
\hline
\end{tabular}

Table 2. Canine heartworm disease in stray dogs according to age group in Grenada West Indies.

\begin{tabular}{cccccc}
\hline \multicolumn{2}{c}{ Dogs } & \multicolumn{3}{c}{ N of $D$. immitis positive dogs (\%) } \\
\hline Age group & N examined & Mild & Moderate & Severe & Total \\
\hline Puppy & 18 & $1(5.6 \%)$ & $1(5.6 \%)$ & $0(0 \%)$ & $2(11.1 \%)$ \\
Juvenile & 24 & $0(0 \%)$ & $3(12.5 \%)$ & $1(4.2 \%)$ & $4(16.7 \%)$ \\
Adult & 481 & $22(4.6 \%)$ & $66(13.7 \%)$ & $50(10.4 \%)$ & $138(28.7 \%)$ \\
\hline
\end{tabular}

\section{Discussion}

In the present study, the overall prevalence of canine heartworm disease in stray dogs in Grenada was $27.5 \%$ (95\% CI: $23.9 \%$ to $31.5 \%$ ). In an earlier study on canine heartworm disease in owned dogs of Grenada, the overall prevalence was estimated at $15.4 \%$ [13]. The current study demonstrates that stray dogs are more affected by $D$. immitis than owned dogs in Grenada. The difference in prevalence values between stray and owned dogs was statistically highly significant $(\mathrm{p}=0.0001)$. Similarly, in the Caribbean island of Turks and Caicos, stray dogs $(58 \%)$ were significantly more affected by $D$. immitis than owned dogs (8\%) [14]. In Northern India, a similar trend with stray dogs (26\% - 30\%) being more infected than owned dogs $(9 \%-11 \%)$ was found [15] [16]. The higher prevalence of $D$. immitis in stray dogs entails lack of prophylaxis in this population of dogs. Stray dogs therefore pose a risk for infection of $D$. nimmitis to owned dogs since they are a major reservoir for this parasite.

The proportion of infected dogs (9\%) in St. Mark was surprisingly lower than expected. During this study, we assumed that St. George would have the lowest prevalence due to the presence of the School of Veterinary Medicine and the Small Animal Clinic in this Parish. On the contrary, in St. Mark there is no veterinary clinic. It is possible that the low prevalence in St. Mark might be due to some prophylactic intervention by private veterinarians before the dogs strayed away. As soon as prophylaxis stops, the dogs become susceptible to D. immitis infection. Thus latest one year after becoming stray dogs, they have the same likelihood for harboring adult $D$. immitis as dogs without prophylactic treatment. 
Thus either stray-dogs get caught relatively quickly in that area or there must be an additional explanation for a low prevalence.

Most of the stray dogs are initially owned and later become stray; resulting in uncontrolled breeding. This is generally due to poor care by dog owners. Prophylaxis is not also routinely done, due to socio-economic constraints.

The variation in the prevalence of $D$. immitis detected by necropsy in different parts of Grenada can only be partially explained. It could be attributed to differences in mosquito vector burdens and dwelling conditions of dogs in the different areas of the country. However, to better understand these mechanisms, further investigations will be needed.

\section{Conclusion}

This study revealed a high prevalence of $D$. immitis in stray dogs, from all six parishes of Grenada. These dogs represent a parasite reservoir and thus a potential risk for infection of owned dogs and even humans [17]. As a consequence, the Ministry of Health and Social Security in collaboration with the Veterinary Division of the Ministry of Agriculture, Lands, Forestry \& Fisheries should continue with the stray dog control program. Effective and reliable medicines for the prophylaxis of $D$. immitis infection in dogs are commercially available. Additionally, the Ministry of Health and Social Security, alongside the One Health One Medicine Program run by St. George's University may provide outreach educational programs regarding regular use of preventative medication for $D$. immitis in dogs and responsible dog ownership.

\section{Acknowledgements}

The authors are grateful to Mr. Ray Samuel and Mr. Derek Thomas for technical assistance.

\section{References}

[1] Genchi, C., Rinaldi, L., Cascone, C., Mortarino, M. and Cringoli, G. (2005) Is Heartworm Disease Really Spreading in Europe? Veterinary Parasitology, 133, 137-148. https://doi.org/10.1016/j.vetpar.2005.04.009

[2] Capelli, G., di Regalbono, A.F., Simonato, G., Cassini, R., Cazzin, S., Cancrini, G., Otranto, D. and Pietrobelli, M. (2013) Risk of Canine and Humanexposure to Dirofilaria immitis Infected Mosquitoes in Endemic Areasof Italy. Parasites \& Vectors, 6, 60. https://doi.org/10.1186/1756-3305-6-60

[3] Montoya-Alonso, J., Carreton, E., Juste, M., Mellado, I., Morchon, R. and Simon, F. (2010) Epidemiological Survey of Canine Heartworm Disease on the Island of Gran Canaria (Canary Islands-Spain) between 2000 and 2008. Veterinary Parasitology, 173, 165-168. https://doi.org/10.1016/j.vetpar.2010.06.008

[4] Polizopoulou, Z., Koutinas, M., Saridomichelakis, M., Patsikas, M., Leontidis, L., Roubies, N. and Desiris, A. (2000) Clinical and Laboratory Observations in 91 Dogs Infected with Dirofilaria immitis in Northern Greece. Veterinary Record, 146, 466-469. https://doi.org/10.1136/vr.146.16.466

[5] Geary, J., Satti, M., Moreno, Y., Madrill, N., Whitten, D., Headley, S., Agnew, D., 
Geary, T. and Mackenzie, C. (2012) First Analysis of the Secretome of the Canine Heartworm, Dirofilaria immitis. Parasites \& Vectors, 5, 140. https://doi.org/10.1186/1756-3305-5-140

[6] Simón, F., Siles-Lucas, M., Morchón, R, González-Miguel, J., Mellado, I., Carretón, E. and Montoya-Alonso, J.A. (2012) Human and Animal Dirofilariasis: The Emergence of a Zoonotic Mosaic. Clinical Microbiology Reviews, 45, 507-544. https://doi.org/10.1128/CMR.00012-12

[7] Bowman, D.D. and Atkins, C.E. (2009) Heartworm Biology, Treatment, and Control. Veterinary Clinics of North America: Small Animal Practice, 39, 1127-1158. https://doi.org/10.1016/j.cvsm.2009.06.003

[8] Labarthe, N. and Guerrero, J. (2005) Epidemiology of Heartworm: What Is Happening in South America and Mexico? Veterinary Parasitology, 133, 149-156. https://doi.org/10.1016/j.vetpar.2005.04.006

[9] Ranjbar-Bahadori, Sh., Eidi Delvarzadeh, M. and Shemshadi, B. (2009) Dirofilaria immitis Infection in Stray Dogs of Khuzestan, a Province in South-Western Iran. International Journal of Veterinary Research, 3, 133-136.

[10] Sanjar, M., Niak, A. and Khatibi, S. (1969) Dirofilariasis in the Dog in Iran. Veterinary Record, 52, 204. https://doi.org/10.1136/vr.85.7.204-a

[11] Kozek, W., Vazquez, A., Gonzalez, C., Jr., Iguina, J., Sanchez, E., Jesus, F. de, Cardona, C., Jr., Gomez, C., Seneriz, R. and Diaz-Umpierre, J. (1995) Prevalence of Canine Filariae in Puerto Rico and the Caribbean. Proceedings of the Heartworm Symposium'95, Auburn, 31 March-2 April 1995, 55-63.

[12] Bowman, D.D. (1999) Georgis' Parasitology for Veterinarians. W.B. Saunders Company, Philadelphia.

[13] Chikweto, A., Bhaiyat, M.I., Lanza-Perea, M., Veytsman, S., Tiwari, K., De Allie, C. and Sharma, R. (2014) Retrospective Study of Canine Heartworm Disease with Caval Syndrome in Grenada, West Indies. Veterinary Parasitology, 205, 721-724. https://doi.org/10.1016/j.vetpar.2014.09.014

[14] Hoff, B., McEwen, B. and Peregrine, A. (2008)A Survey for Infection with Dirofilaria immitis, Ehrlichia canis, Borrelia burgdorferi, and Babesia canis in Feral and Client-Owned Dogs in the Turks and Caicos Islands, British West Indies. Canadian Veterinary Journal, 49, 593-594.

[15] Bhattacharjee, K. and Sarmah, P. (2014) Epidemiological Aspects of Dirofilaria immitis Infection in Dogs from Assam of Northeast India. Asian Pacific Journal of Tropical Disease, 4, S255-S258. https://doi.org/10.1016/S2222-1808(14)60450-3

[16] Borthakur, K., Deka, D., Islam, S., Sarma, D. and Sarmah, P. (2015) Prevalence and Molecular Epidemiological Data on Dirofilaria immitis in Dogs from Northeastern States of India. The Scientific World Journal, 2015, Article ID: 265385, 7 p.

[17] Simón, F., Morchon, R., Gonzalez-Miguel, J., Marcos-Atxutegi, C. and Siles-Lucas, M. (2009) What Is New about Animal and Human Dirofilariosis? Trends in Parasitology, 25, 404-409. https://doi.org/10.1016/j.pt.2009.06.003 